\title{
Populasi dan Karakteristik Habitat Tarsius (Cephalopachus bancanus borneanus) di Punggualas, Taman Nasional Sebangau
}

\author{
Population and Habitat Characteristics of Tarsier (Cephalopachus \\ bancanus borneanus) in Punggualas, Sebangau National Park
}

\author{
Robby Octavianus \\ Jurusan Kehutanan, Fakultas Pertanian, Universitas Palangka Raya
}

Alamatemail: robi@for.upr.ac.id

\begin{abstract}
Abstrak - Tarsius (Cephalopachus bancanus borneanus) adalah salah satu primata endemik di Kalimantan. IUCN (International Union for the Conservation of Nature and Natural Resources) telah menetapkan status konservasi Cephalopachus bancanus borneanus sebagai satwa vulnerable. Penelitian ini dilaksanakan di kawasan Punggualas, Taman Nasional Sebangau, dari bulan Juni hingga Agustus 2019. Data yang dikumpulkan adalah jumlah dan sebaran populasi tarsius berserta komposisi dan struktur vegetasi. Studi ini mengungkapkan bahwa tarsius di Punggualas memiliki kecenderungan untuk hidup secara soliter. Total 6 individu tarsius yang dijumpai dalam lingkup area seluas 4 km ${ }^{2}$, dengan total panjang transek mencapai $22 \mathrm{~km}$. Populasi di lingkup areal penelitian adalah sebesar 23 individu yang menempati areal seluas $4 \mathrm{~km}^{2}$ dengan kepadatan populasi sebesar 5,682 individu/ $\mathrm{km}^{2}$. Kerapatan vegetasi di Punggualas mencapai 1179 individu per hektar pada tingkatan pancang, dimana kawasan ini menjadi habitat yang sesuai untuk berlindung, bergerak dan sebagai tempat beristirahat (tidur) bagi tarsius.
\end{abstract}

Kata Kunci : Tarsius, Punggualas, soliter, populasi, habitat.

Abstract - Tarsier (Cephalopachus bancanus borneanus) is one of the endemic primates in Kalimantan. IUCN (International Union for the Conservation of Nature and Natural Resources) has established the conservation status of Cephalopachus bancanus borneanus as a vulnerable primate. This research was conducted in the Punggualas area, Sebangau National Park, from June to August 2019. The data collected was the number and distribution of tarsier population along with the composition and structure of vegetation. This study revealed that tarsiers in Punggualas have a tendency to live solitary. A total of 6 tarsier individuals were found in an area of $4 \mathrm{~km}^{2}$, with a total length of $22 \mathrm{~km}$ of transects. The population in the scope of the study area is 23 individuals who occupy an area of $4 \mathrm{~km} 2$ with a population density of 5,682 individuals / $\mathrm{km}^{2}$. The density of vegetation in Punggualas reaches 1179 individuals per hectare at the sapling level, where this area is a suitable habitat for shelter, locomoting, and as sleeping site for Tarsiers.

Keywords : Tarsier, Punggualas, solitary, population, habitat.

(c) 2020 Jurnal Jejaring Matematika dan Sains. This work is licensed under a CC BY-NC 4.0

\section{PENDAHULUAN}

Tarsius merupakan salah satu primata terkecil dimuka bumi. Primata yang termasuk dalam famili Tarsiidae ini memiliki ukuran tubuh hanya berkisar $12-15 \mathrm{~cm}$. Satwa ini adalah primata nokturnal yang memiiki mata merah besar dan bulat. Tarsius memiliki habitat di berbagai tipe, dari hutan primer, hutan sekunder, hutan bakau, kebun yang berada di dekat hutan, bahkan di belukar bambu serta semak belukar.

Saat ini famili Tarsiidae memiliki tiga genus, yaitu Cephalopachus (Western Tarsier), Carlito (Philippine Tarsier), dan Tarsius (Eastern Tarsier) [5]. Groves et al (2010) membagi 3 genus tersebut berdasarkan distribusi secara allopatrik dalam perbedaan wilayah biogeografis: Tarsius ditemukan di Sulawesi dan pulau-pulau di sekitarnya; Cephalopachus ditemukan pada subset terbatas Kepulauan Sunda, terutama selatan bagian dari Sumatera dan pulau Kalimantan; Carlito ditemukan di pulau-pulau selatan Filipina yang merupakan daratan tunggal pada zaman es, kadang-kadang disebut Mindanao
Besar. Genus Cephalopachus sendiri hanya memiliki satu spesies, yaitu $C$. bancanus dengan empat subspesies, yaitu C. b. bancanus, C. b. saltator, C. b. natunensis, dan $C$. $b$. borneanus [11]. Adapun C. bancanus memiliki banyak nama lokal, salah satunya dinamakan Ingker oleh masyarakat dayak di Kalimantan Tengah pada umumnya.

IUCN (International Union for the Conservation of Nature and Natural Resources) telah menetapkan status konservasi Cephalopachus bancanus sebagai satwa vulnerable (VU; rentan) [6]. Namun untuk status konservasi sub spesiesnya memiliki tingkatan yang berbeda-beda, seperti Cephalopachus bancanus borneanus sebagai satwa VU, Cephalopachus bancanus bancanus dan Cephalopachus bancanus saltator sebagai satwa endangered (EN; genting atau terancam), serta Cephalopachus bancanus natunensis sebagai satwa critically endangered (CR; kritis) [11]. Selain itu, Pemerintah Indonesia lebih dulu melindungi semua spesies Tarsiidae di Indonesia dengan Peraturan Pemerintah No. 7 Tahun 1999 tentang Pengawetan Jenis Tumbuhan dan Satwa. 
Penetapan status konservasi dari Cephalopachus bancanus sendiri didasari pada berkurangnya jumlah populasinya di alam. Penyebabnya sendiri antara lain semakin berkurangnya habitat akibat konversi hutan menjadi perkebunan kelapa sawit berskala besar, lahan pertambangan, pemukiman penduduk, perambahan hutan secara ilegal, serta kebakaran hutan dan banjir [6].

Dikarenakan status konservasinya yang rentan, berbagai upaya perlu dilakukan untuk tetap menjaga dan melestarikan kehidupan dan populasinya di alam liar. Berdasarkan data yang terpublikasi baik jurnal, laporan penelitian dan data lainnya, informasi mengenai densitas maupun sebaran populasi dari tarsius ini sangatlah sedikit. Niemitz mencatat densitas populasi $C$. b. borneanus diketahui kurang dari 80 ekor $/ \mathrm{km}^{2}$ di Serawak [9,10], Crompton dan Andau mencatat sekitar 14-20 ekor/ $\mathrm{km}^{2}$ di Sabah [3,4], dan Graham mencatat 0,003 ekor $/ \mathrm{km}^{2}$ di Sebangau [2]. Data data tersebut diatas memiliki kesenjangan waktu yang jauh, sehingga diperlukan data terbaru untuk lebih mengetahui keberadaan dan keadaan populasinya di alam liar.

Punggualas yang merupakan bagian dari Taman Nasional Sebangau ditunjuk sebagai Pusat Informasi dan Pariwisata, karena di daerah ini banyak ditemukan berbagai macam satwa dan vegetasi endemik hutan rawa gambut. Di daerah ini juga merupakan pusat penelitian Orangutan yang diinisiasi oleh Balai Taman Nasional dan WWF Indonesia Kalimantan Tengah, Punggualas sebagai pusat penelitian dimulai dari tahun 2010 .

Tarsius di Punggualas, berdasarkan komunikasi dengan masyarakat lokal setempat, sering dijumpai. Satwa ini sering dijumpai di sekitar pohon yang memiliki lubang pada pohonnya, yang kemungkinan besar merupakan pohon tidurnya. Satwa ini juga sering dijumpai pada saat siang hari pada sekitar pohon Lunuk atau Beringin (Ficus $s p)$.

Dari beberapa keterangan diatas, masih banyak hal yang tidak ketahui dari spesies ini. Hasil dari penelitian ini diharapkan mampu menambah informasi mengenai tarsius di kawasan Punggualas yang termasuk ke dalam Taman Nasional Sebangau, dan sebagai bahan referensi mengenai status konservasi tarsius yang ada sekarang di kawasan Punggualas.

Adapun tujuan dari penelitian ini adalah untuk mengetahui sebaran dan karakteristik habitat tarsius di kawasan Punggualas

\section{METODE PENELITIAN}

\section{A. Sebaran dan Populasi Tarsius}

Penelitian ini dilakukan pada bulan Juni - Agustus 2019 di Taman Nasional Sebangau, berlokasi di kawasan hutan Punggualas seperti yang terdapat dalam Gambar 1. Alat yang digunakan dalam penelitian ini antara lain : kamera, GPS, meteran gulung, tambang, tali rafia, tally sheet, alat tulis.

Penelitian dilakukan dengan pengamatan langsung di area penelitian meliputi pengambilan data kondisi fisik, komposisi vegetasi dan jumlah populasi beserta sebarannya.

Metode yang digunakan dalam penelitian ini adalah metode systematic sampling with random start. Metode ini menggunakan line transect yang sudah dibuat untuk pengamatan perilaku Orangutan di Punggualas. Luasan yang ditetapkan sebagai areal penelitian tarsius ini adalah $4 \mathrm{~km}^{2}$.

Pengambilan data dilakukan dengan berjalan menelusuri areal antara jalur jalur transek dan mencatat data yang diperlukan, antara lain : Jam pertemuan; Jarak pada transek (koordinat GPS); Jarak tegak lurus dari objek ke transek; Jenis objek dan jumlah (individu/pohon tidur/suara/bau urin); Tinggi objek (apabila perjumpaan dengan individu/pohon tidur); Jenis pohon tidur (apabila perjumpaan dengan individu/pohon tidur); DBH pohon tidur (apabila perjumpaan dengan individu/pohon tidur)

Analisis data sebaran tarsius dilakukan dengan membuat peta menggunakan software ArcGIS dan juga dilakukan perhitungan kepadatan populasinya dengan menggunakan rumus yang dikembangkan oleh Pusat Penelitian dan Pengembangan Perubahan Iklim dan Kebijakan, Badan Penelitian dan Pengembangan Kehutanan [1]:

$$
\text { Densitas (D) }=\frac{\mathrm{n}}{2 \mathrm{Lw}},
$$

sedangkan untuk penentuan perkiraan jumlah populasi menggunakan rumus:

$$
\text { Perkiraan Populasi }(E P)=\frac{A n}{2 L w},
$$

\section{B. Karakteristik Habitat}

Pengambilan data difokuskan pada area pertemuan atau pohon tidur dari tarsius. Metode karakteristik habitat tarsius dilakukan dengan metode kuadrat [8]. Pohon dianalisis dalam petak kuadrat ukuran $20 \mathrm{~m}$ x $20 \mathrm{~m}$, tiang dalam petak kuadrat ukuran $10 \mathrm{~m} \times 10 \mathrm{~m}$, dan pancang dalam kuadrat petak ukuran $5 \mathrm{~m}$ x $5 \mathrm{~m}$; sedangkan anakan pada petak kuadrat ukuran $2 \mathrm{~m}$ x $2 \mathrm{~m}$. Setiap ukuran petak diletakkan di sekitar habitat tarsius terutama habitat tidurnya.

Analisis vegetasi pada karakteristik habitat tarsius dilakukan dengan perhitungan terhadap parameter kuantitatif vegetasi. 


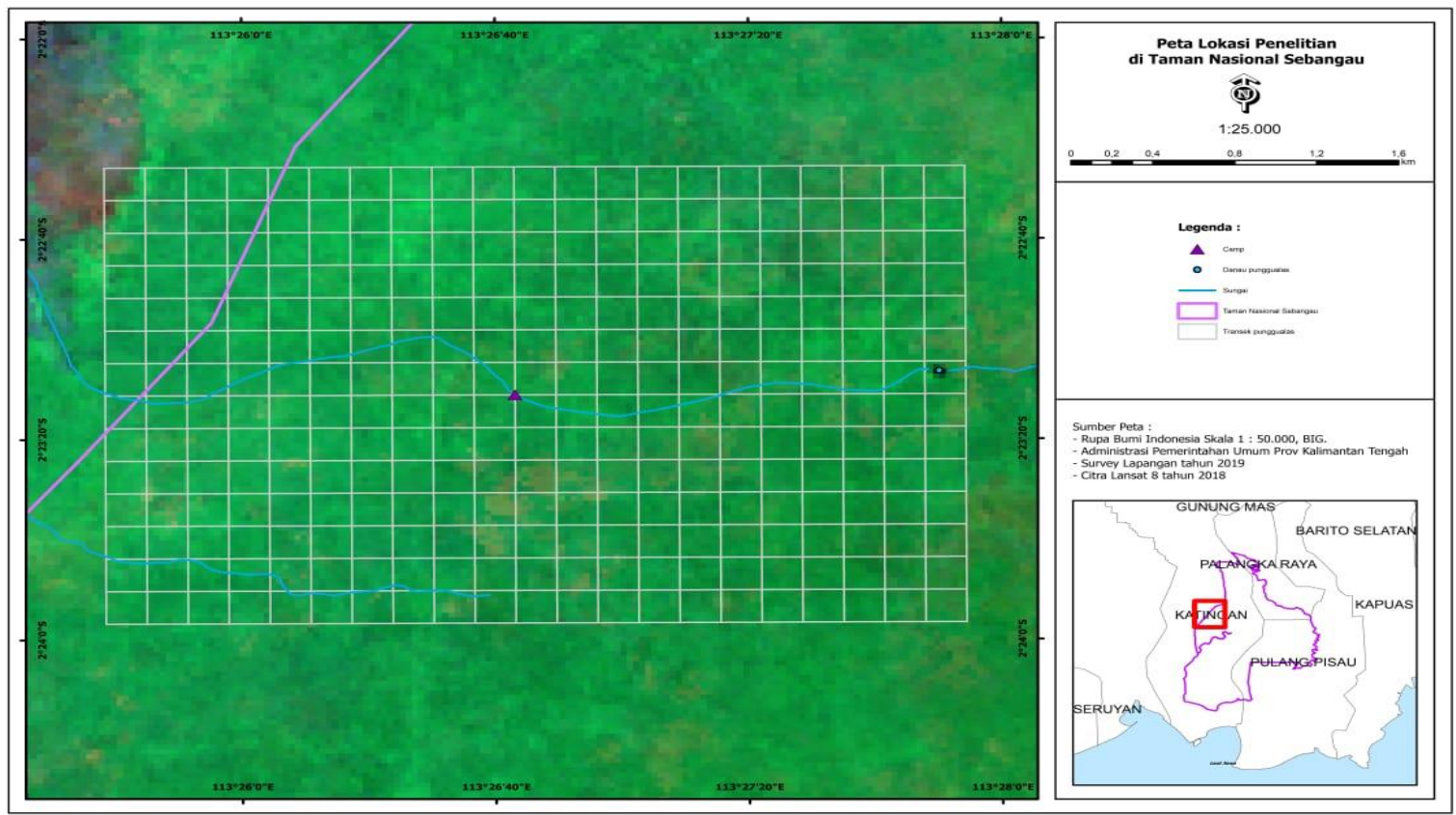

Gambar 1. Lokasi penelitian tarsius di kawasan Punggualas

\section{HASIL DAN PEMBAHASAN}

\section{A. Populasi dan Sebaran Tarsius}

Total 6 individu tarsius yang dijumpai dalam lingkup area seluas $4 \mathrm{~km}^{2}$, dengan total panjang transek mencapai $22 \mathrm{~km}$. Titik sebaran perjumpaan dengan tarsius di kawasan Punggualas dapat dilihat pada gambar 2 dibawah

Berdasarkan jumlah populasi yang dihitung berdasarkan data lapangan, populasi di lingkup areal penelitian adalah sebesar 23 individu yang menempati areal seluas $4 \mathrm{~km}^{2}$ dengan kepadatan atau densitas populasi sebesar 5,682 individu $/ \mathrm{km}^{2}$. Populasi ini masih jauh lebih rendah dari data yang dikeluarkan oleh Niemitz $[9,10]$ dengan jumlah populasi sebesar 80 individu $/ \mathrm{km}^{2}$. Namun apabila dibandingkan dengan perhitungan populasi yang dilakukan oleh Syafutra [13] yang dilakukan di pulau Bangka dengan rentang populasi antara 2,22 - 17,78 individu $/ \mathrm{km}^{2}$, hasil penelitian ini hampir mendekati.

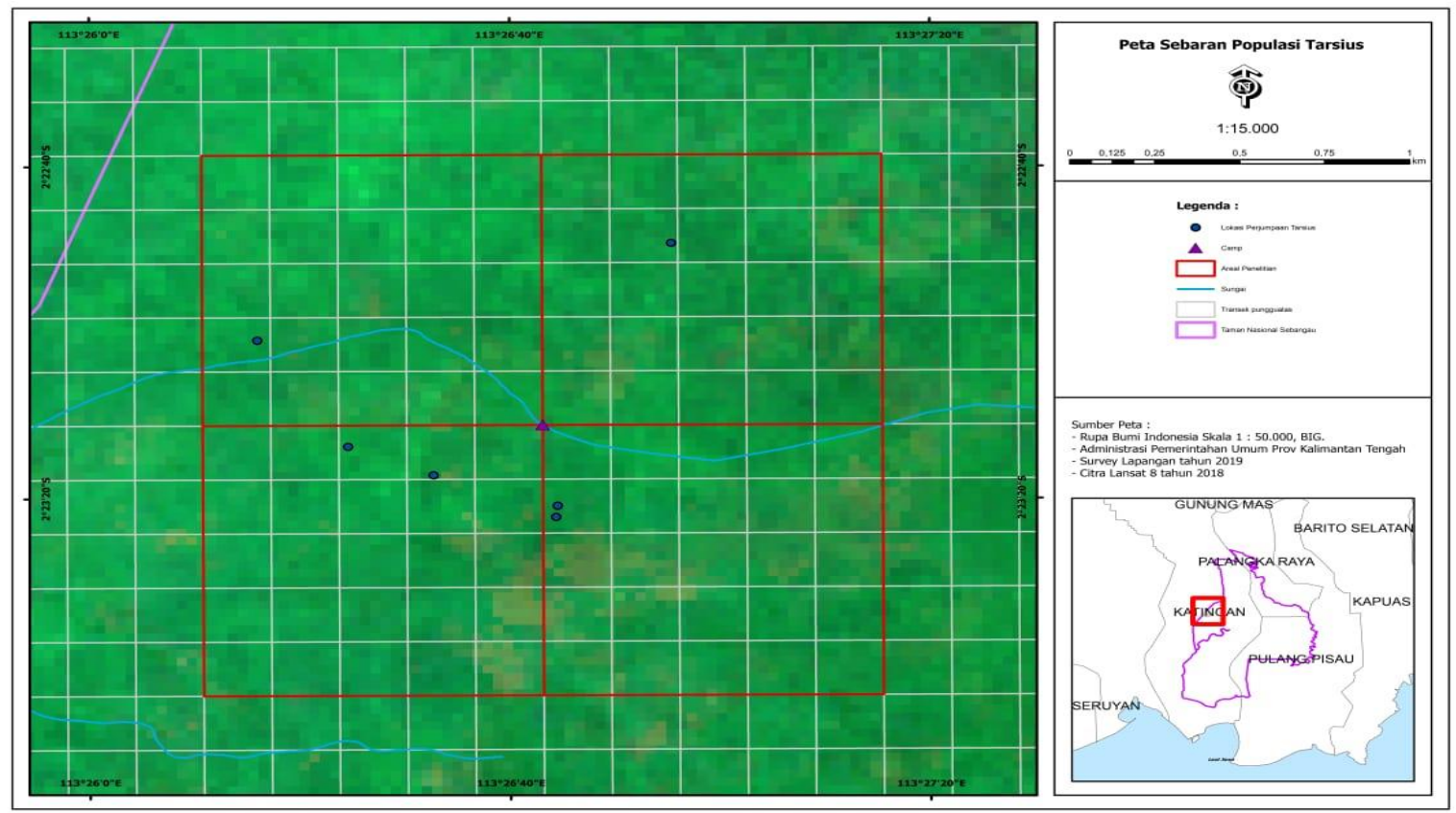

Gambar 2. Peta titik sebaran perjumpaan tarsius di Punggualas

Tarsius diketahui hidup dan berkembang biak pada berbagai tipe habitat yang berbeda struktur tegakannya, seperti hutan primer, hutan sekunder, tepi perkebunan, dan di sepanjang pesisir pantai dengan semak belukar $[7,9,12]$. 
Tarsius dijuga mendiami belukar-belukar bambu yang padat dan kadangkala ditemukan di kebun dekat hutan [14] [15]. Selain itu, tarsius juga pernah ditemukan di hutan bakau dan semak belukar [16]. Meskipun tarsius dapat hidup dan berkembang biak pada berbagai tipe habitat yang berbeda struktur tegakannya, namun Yasuma dan Alikodra menyatakan habitat yang paling disukai tarsius adalah hutan hujan tropis dengan sumber air melimpah yang dapat mendukung ketersediaan makanan, serta hutan sekunder dengan pohon-pohon yang berukuran kecil dan sedang. Adapun western tarsier (C. bancanus) pada umumnya lebih memilih muncul di tepi hutan sekunder dengan pohon muda yang berlimpah dan vegetasi sekunder lainnya [12].

Di kawasan Punggualas, tarsius dijumpai pada hutan rawa gambut sekunder, yaitu hutan yang memiliki tingkatan pancang dan tiang yang rapat. Berdasarkan pengamatan di lapangan, tarsius lebih banyak menggunakan pohon yang memiliki diameter dibawah 10 $\mathrm{cm}$ untuk pergerakannya. Ini dikarenakan tarsius harus merangkul pohon tersebut agar memiliki posisi yang kuat untuk berpijak ataupun bertengger.

Sebaran kelompok tarsius yang ditemukan di Punggualas, keseluruhannya ditemui pada areal yang memiliki tingkatan pancang dan tiang yang rapat. Berdasarkan pengamatan, ini untuk memudahkan perpindahan dan pergerakan dari tarsius tersebut. Kondisi lantai hutan pada areal tempat perjumpaan dengan tarsius dalam kondisi tidak tergenang air, walaupun secara umum kawasan Punggualas merupakan lahan rawa gambut.

Dari data yang diperoleh, persebaran tarsius cenderung berada di pinggiran sungai, antara 40 - 200 meter. Jika dilihat secara umum, persebaran ini dipengaruhi mungkin oleh struktur vegetasi penyusunnya, dikarenakan vegetasi yang semakin berada di pinggiran sungai akan cenderung memiliki diameter kecil dan rapat, dan jenisnya juga akan beragam, dan semakin menjauh dari pinggiran sungai, vegetasinya akan memiliki diameter yang besar dan keragamannya juga akan berkurang.
Berdasarkan data dilapangan, tarsius di kawasan Punggualas dominan ditemukan hanya satu (1) individu atau soliter. Terdapat 1 kali pertemuan dimana ditemukan tarsius dewasa dengan anaknya. Namun secara pasti dikatakan tarsius di Punggualas kemungkinan besar merupakan hewan yang soliter, dan tidak hidup berkelompok besar seperti yang ditemukan di daerah Sulawesi. Namun hal ini perlu kajian lebih lanjut, dikarenakan data data yang sudah diperoleh belum mampu menyatakan hal tersebut diatas adalah benar.

Apabila mengacu terhadap penelitian sebelumnya yang dilakukan di kawasan gambut, jumlah ini dapat dikatakan cukup besar untuk pertemuan individunya. Struktur hutan di rawa gambut kawasan Punggualas yang sebagian besar memiliki tingkatan pancang dan tiang yang rapat mengakibatkan jarak pandang pada malam hari sangatlah kurang, walaupun dengan bantuan senter. Kerapatan tumbuhan yang "intens" mampu memberikan perlindungan terhadap pemangsa bagi individu seperti tarsius. Hal ini juga yang mungkin mengakibatkan kurangnya pertemuan dengan satwa ini di kawasan Punggualas. Dengan tubuhnya yang kecil, satwa ini mampu berpindah secara cepat dan tidak terdekteksi, ditambah dengan perlindungan dari keadaan sekitar, kemungkinan untuk bertemu dengan tarsius sangatlah kecil.

\section{B. Karakteristik Habitat}

Dari hasil analisis vegetasi didapatkan 43 jenis vegetasi dengan jumlah 571 individu yang mewakili karakteristik habitat tarsius. Jika dijabarkan lebih lanjut berdasarkan tingkat pertumbuhan maka; Tingkatan Pohon memiliki 25 jenis dengan 76 individu, tingkatan Tiang memiliki 26 jenis dengan 67 individu, tingkatan Pancang memiliki 30 jenis dengan 283 individu;dan tingkatan Semai memiliki 12 jenis dengan 145 individu. Pada tabel 1 dibawah memperlihatkan tingkat kerapatan 3 jenis tumbuhan teratas pada setiap tingkatan pertumbuhan.

Tabel 1. Jenis tumbuhan dominan pada setiap tingkatan pertumbuhan

penelitian, maka dapat meningkatkan regenerasi yang baik pada ekosistem tersebut [19].

\begin{tabular}{lllcc}
\hline Tingkatan & Nama Jenis & Nama Ilmiah & Kerapatan & INP \\
\hline Semai & Sagagulang & Acronychia pedunculata & 250,000 & 62,808 \\
Semai & Kemuning & Xanthophyllum sp. & 104,167 & 35,099 \\
Semai & Tutup Kabali & Diospyros pseudo-malabrica & 83,333 & 31,650 \\
\hline Pancang & Tutup Kabali & Diospyros pseudo-malabrica & 179,167 & 23,414 \\
Pancang & Belawan & Tristaniopsis obovata & 150,000 & 19,570 \\
Pancang & Sagagulang & Acronychia pedunculata & 91,667 & 15,993 \\
\hline Tiang & Sagagulang & Acronychia pedunculata & 45,833 & 51,808 \\
Tiang & Kamasira & Ilex cymosa & 29,167 & 30,867 \\
Tiang & Terantang & Camnosperma coriaceum & 25,000 & 29,621 \\
\hline Pohon & Meranti & Shorea spp. & 58,333 & 47,467 \\
Pohon & Terantang & Camnosperma coriaceum & 33,333 & 29,374 \\
Pohon & Daha Bahandang & Horsfielda sp. & 25,000 & 27,484 \\
\hline
\end{tabular}

Whitmore menyebutkan jika tingkat pancang maupun semai yang paling banyak mendominasi di lokasi
Berdasarkan data analisis vegetasi, pada gambar 3 dapat dilihat bahwa kerapatan total vegetasi pada tingkatan pertumbuhan Pancang memiliki nilai yang cukup besar, 
mencapai 1179 individu per Ha. MacKinnon dan MacKinnon melaporkan bahwa tarsius membutuhkan cabang pohon dengan diameter kecil $(<4 \mathrm{~cm})$ terutama untuk berburu dan menjelajah. Diameter sedang $(4-8 \mathrm{~cm})$ terutama digunakan untuk istirahat dan menandai daerah jelajah (home range), sedangkan diameter $>8 \mathrm{~cm}$ juga digunakan untuk istirahat dan menandai daerah jelajah (home range) meskipun tidak sebanyak diameter sedang [7].

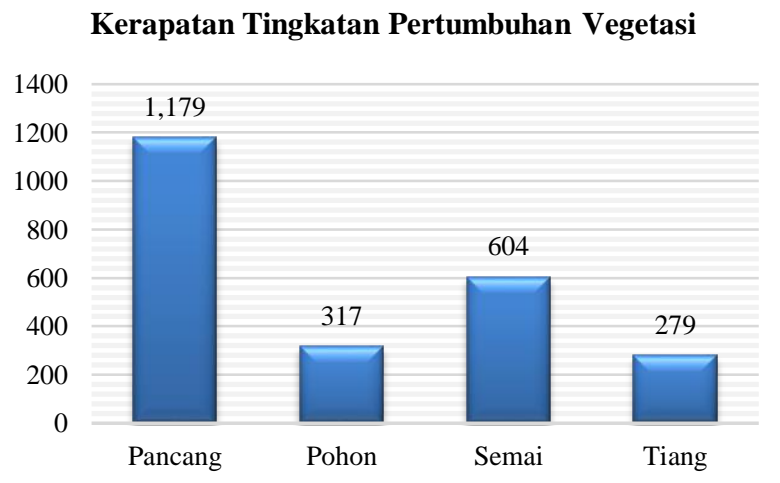

Selain diameter pohon, tingkat kerapatan dan penutupan pohon juga berpengaruh terhadap keberadaan tarsius. Crompton \& Andau menjelaskan bahwa vegetasi berperan bagi kehidupan tarsius terutama sebagai tempat untuk berlindung, bergerak dan sebagai tempat beristirahat (tidur) [3].

Di kawasan Punggualas sendiri, lokasi potensial untuk pertemuan dengan tarsius adalah di daerah yang memiliki struktur vegetasi tingkat pancang dan tiang yang rapat, dan memiliki keragaman jenis pohon yang beragam. Dari data yang diperoleh ada 5 jenis pohon tempat pertemuan dengan tarsius, yaitu Sagagulang, Tapohot, Madang Perawas, Tampang Gagas dan Gandis, yang berdiamater antara 1 sampai dengan $10 \mathrm{~cm}$. Pada Gambar 4 dibawah dapat dilihat beberapa pohon yang menjadi tempat pertemuan dengan tarsius. Dari gambar tersebut membuktikan satu hal yang memastikan bahwa tarsius menggunakan vegetasi yang berukuran kecil untuk melakukan lokomosi atau pergerakannya sehari hari.

Tarsius merupakan satwa pemakan serangga sehingga tidak memanfaatkan tumbuhan sebagai sumber makanan namun kondisi vegetasi sangat menentukan jenis dan jumlah serangga yang dapat ditemukan di suatu daerah tertentu. Selain itu, kompleksitas vegetasi seperti keanekaragaman spesies, kepadatan tajuk, kepadatan pohon, keberadaan semak belukar, dan rerumputan memberikan pengaruh terhadap komposisi sumberdaya di suatu tempat. Kerapatan vegetasi juga digunakan oleh tarsius untuk menjalankan aktifitasnya sehari-hari seperti tempat untuk bergerak, mencari pakan, bermain, istirahat dan bersarang.
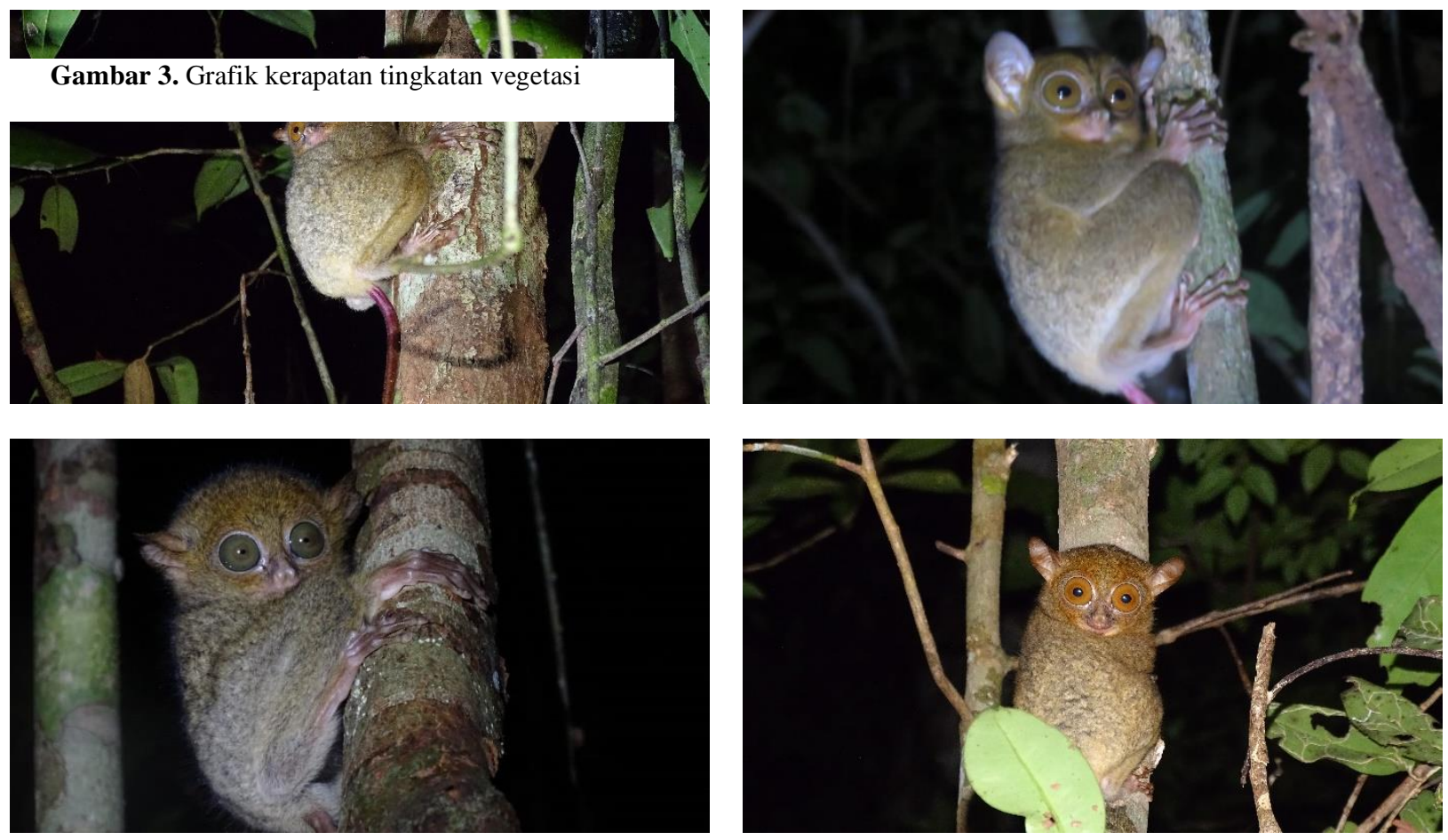

\section{SIMPULAN}

Berdasarkan hasil penelitian dilapangan dapat diperoleh kesimpulan yaitu perhitungan kepadatan populasi tarsius di areal penelitian adalah sebesar 5,682 individu $/ \mathrm{km}^{2}$

berada di sekitar pinggiran sungai dengan kisaran 40 - 200 meter. Karakterisitik habitat tarsius di areal peneltian disusun oleh 43 jenis vegetasi dengan jumlah 571 individu, dengan tingkatan pertumbuhan vegetasi pancang yang

Gambar 4. Foto individu tarsius yang ditemukan di lokasi penelitian

dengan perkiraan populasinya dengan luasan total $4 \mathrm{~km}^{2}$ adalah sebesar 22,727 individu. Tarsius di Punggualas cenderung untuk hidup soliter dengan sebaran individu memiliki kerapatan terbesar dari ke empat (4) tingkatan pertumbuhan vegetasi lainnya. 
Berdasarkan hasil penelitian, saran yang perlu menjadi perhatian adalah perlu adanya standarisasi metode penelitian terkait pendugaan kepadatan populasi tarsius, sehingga ke depan akan memiliki persepsi dan asumsi yang sama. Perlu dilakukan penelitian serupa di lokasi yang berbeda, agar diperoleh data yang akurat mengenai populasi tarsius, khususnya untuk spesies Cephalopachus bancanus borneanus. Perlu adanya studi lanjutan terkait dengan persebaran tarsius, terutama di lokasi yang diperkirakan memiliki populasi yang besar, sebagai upaya pelestarian habitat dan populasinya.

\section{REFERENSI}

[1] Bismark, M. 2011. Prosedur Operasi Standar (SOP) untuk survei keragaman jenis pada kawasan konservasi. Pusat Penelitian dan Pengembangan Perubahan Iklim dan Kebijakan, Badan Penelitian dan Pengembangan Kehutanan. Bogor.

[2] Blakham, Grace. 2005. Pilot survey of nocturnal primates, Tarsius bancanus borneanus (Western tarsier) and Nycticebus coucang menagensis (Slow loris) in peat swamp forest, Central Kalimantan, Indonesia.

[3] Crompton RH, Andau PM. 1986. Locomotion and habitat utilization in free-ranging Tarsius bancanus: A preliminary report. Primates 27(3): 337-355.

[4] Crompton RH, Andau PM. 1987. Ranging, activity rhythms, and sociality in free-ranging Tarsius bancanus: A preliminary report. Intl J Primatol 8: 43-71.

[5] Groves, Colin \& Shekelle, Myron. 2010. The Genera and Species of Tarsiidae. International Journal of Primatology. 31. 1071-1082. 10.1007/s10764-010-9443-1.

[6] IUCN, "IUCN Red List", 01 April 2019, [Online]. Tersedia: https://www.iucnredlist.org. [Diakses: 01 April 2019].
[7] MacKinnon J, MacKinnon K. 1980. The behaviour of wild spectral tarsiers. International Journal of Primatology. 1(4): 361-379.

[8] Mueller-Dombois, Dieter \& Ellenberg, Heinz. 1974. Aims and methods of vegetation ecology.

[9] Niemitz C. 1979. Outline of the Behavior of Tarsius bancanus. Di dalam: Doyle GA, Martin RD, editor. 1979. The Study of Prosimian Behavior. New York (US): Academic Pr.

[10] Niemitz C, editor. 1984. Biology of Tarsiers. Stuttgart (DE): Fischer Verlag.

[11] Roos, Christian \& Boonratana, Ramesh \& Supriatna, Jatna \& Fellowes, John \& P. Groves, Colin \& Nash, Stephen \& Rylands, Anthony \& Mittermeier, Russell. 2014. An updated taxonomy and conservation status review of Asian primates. Asian Primates Journal. 4. 2-38.

[12] Wolfheim JH. 1983. Primates of the World: Distribution, Abundance and Conservation. London (GB): Washington University Pr.

[13] Syafutra, R. 2016. Habitat and Population of Mentilin (Cephalopachus bancanus bancanus) in Bangka Regency. Thesis. Institut Pertanian Bogor. Bogor.

[14] Napier JR, Napier PH. 1967. A Handbook of Living Primates. London (GB): Academic Pr.

[15] Supriatna J, Wahyono EH. 2000. Panduan Lapangan Primata Indonesia. Yayasan Obor Indonesia. Jakarta.

[16] Wright PC, Simons EL, Gursky S. 2003. Tarsiers: Past, Present, and Future (Rutgers Series in Human Evolution). New Brunswick, Canada (CA): Rutgers University Pr.

[17] Yasuma S, Alikodra HS. 1990. Mammals of Bukit Soeharto Protection Forest. The Tropical Rain Forest Research Project. Kalimantan Timur.

[18] Septiyani, Y. 2010. Struktur Komunitas dan Regenerasi Tegakan Hutan di Kawasan Konservasi Taman Margasatwa Ragunan Jakarta Selatan. [Skripsi] Jakarta: Fakultas Biologi Universitas Nasional.

[19] Whitmore, T. C. 1986. Tropical Rain Forest of The Far East. Oxford Iniversity Press.. 